\title{
Cross-cultural rhetoric awareness and writing strategies of EFL learners: Implications for writing pedagogy
}

\author{
Ghanbari, Batoul $\bowtie$ \\ Persian Gulf University, Bushehr, Iran (btghanbari@gmail.com)
}

Received: 11 November 2013

Available Online: 24 February 2014
Revised: 15 January 2014 DOI: $10.5861 /$ ijrsll.2014.620

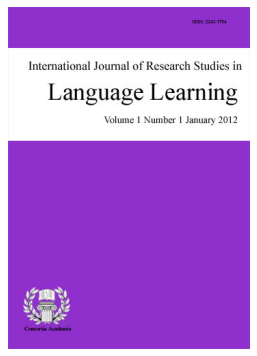

Accepted: 21 January 2014 Online ISSN: 2243-7762

OPEN ACCESS

\section{Abstract}

This study investigates how differences in rhetoric awareness relate to differences in English as a Foreign Language (EFL) writing strategies employed by learners in a context of an Iranian English language institute. It is hypothesized that learners with extensive exposure to English rhetorical and cultural preferences for essay organization and argument structure resources may have a better command of the nuances of rhetorical structure than those who do not. In order to know if such a difference has any implication for the use of composition strategies, a group of 22 advanced learners in a language institute were asked to take a discourse cloze test designed in a way to measure their awareness of English rhetoric. Upon the completion of the test, two groups ( $N=10$ in each) of English rhetoric aware and rhetoric unaware participants were formed. Later, two learners were randomly selected from each group to verbalize their thoughts when writing an argumentative essay. The analysis of the think aloud protocols along with the following stimulated recall interviews with them revealed noticeable qualitative and quantitative differences in strategy use between the English rhetoric aware and unaware writers. Findings of the study suggest that along with a new turn in contrastive rhetoric studies on the one hand and post-process movement in writing on the other hand, wider perspectives in contrastive rhetoric studies which incorporates process and cognitive views when delineating issues in writing pedagogy should be taken into account.

Keywords: contrastive rhetoric; process approach; writing strategies; rhetoric aware; rhetoric unaware; EFL writing 


\section{Cross-cultural rhetoric awareness and writing strategies of EFL learners: Implications for writing pedagogy}

\section{Introduction}

Initiated by Kaplan's pioneering study (1966), contrastive rhetoric (henceforth CR) considers language and writing to be culturally value-laden and introduces L1 transfer as the main obstacle for writing effectively in L2. Consequently, each language is assumed to have its unique rhetorical conventions and writers' cultural backgrounds influence their organization of writing in what they choose to use as evidence in supporting their main ideas; how they express their main ideas; and how they write in the foreign language (Benda, 1999).

It did not take long that these early assumptions of CR were challenged on many grounds. Identifying some caveats in the early assumptions of CR, many scholars including Kaplan himself attempted to qualify and elaborate the original claims of CR. Simplistic methodology and naïve conceptualization of CR (Martin,1992; Matsuda, 1997), overgeneralizing and stereotyping about rhetorical conventions (Leki, 1991, 1997), ignoring L2 developmental variables or the hardship L2 learners might face in the process of writing (Mohan \& Lo, 1985) were some of the harsh criticisms leveled against early CR.

Among the above criticisms, the turn to the process of writing rather than a focus on the mere product of writing (i.e. text) has broadened out the body of factors which might account for the difficulties L2 writers might experience in composing a text and it subsequently put the generalities of CR into the test of practice. This innovative line of research has been mentioned as new CR in the literature (Liebman, 1992). In fact, general tone of original CR researchers (e.g. Kaplan, 1966) which ascribed any failures in L2 writing to the cultural and linguistic differences cannot be sustained anymore. Rather, the new movement maintains that a deeper analysis which explores the how of the composition process would yield a more perfect picture of the variables involved.

In accord with the above interest into the process of writing and this fact that understanding writing strategies is indispensable to helping EFL learners develop their writing abilities (Lei, 2008), studies were launched which focused on the mental processes of writers when composing a text. In fact, the call by Braddock, Lloyd-Jones, and Schoer (1963) for investigation into the process of composition and studying the behaviors and strategies that writers evoke has bred a considerable body of research in both L1 and L2 writing (Bosher, 1998; Casanave, 2002; Cohen \& Brooks-Carson, 2001; Cumming, 1989; Leki,1995,1998; Raimes, 1987; Roca de Larios, Manchon, Murphy, \& Marın, 2008; Roca de Larios, Murphy, \& Manchon, 1999; Sasaki, 2000, 2002, 2004, 2007; Villamil \& de Guerrero, 1996; Wong, 2000, 2005; Zamel, 1982, 1983).

However, findings have been partial since the studies have been mostly framed within a pure cognitive view often at the expense of other contextual elements involved. But, this promising integration of cognitive and contextual camps prepared the ground to look into the process of writing with a more firm theoretical and methodological basis (Currie, 1993; Leki, 1995; Riazi, 1997; Hansen, 2000).

In the words of Horowitz (1986), the form in which a writer expresses meaning owes equally to both the constraints of the writing situation and the writers' mental processes. Needless to say, rhetoric as a subset of the wider contextual and cultural leanings which forms the perceptions of the writers regarding audience, purpose, organizational structure, mode of thinking, etc. has some bearings on the process of composing a text and consequently it would be an innovative area to study within the same balanced perspective to L2/FL composition.

Therefore, following this new line of inquiry, present study was undertaken to probe the issue that to what extent awareness of EFL rhetorical elements affects the strategic behavior of a group of Iranian EFL learners when involved in the writing task. That is to what extent rhetoric-awareness is reflected in the quantity 
Cross-cultural rhetoric awareness and writing strategies of EFL learners: Implications for writing pedagogy

and quality of the strategies employed by the learners. It is hoped that present study would enrich our knowledge regarding the influence of rhetorical factors on the process of composing a text. Furthermore, any findings about the how of writing process would provide contrastive rhetoricians with a more empirically-based appraisal of CR claims.

Moreover, findings would aid EFL writing practitioners to look beyond writing as a cognitive and mental classroom activity but a socially and culturally-embedded one. It suggests EFL learners to consider writing beyond the stage-like view emphasized in the process perspective and helps them to promote their narrow and mechanical view towards a multi-faceted one when composing a text in English. Also, awareness of rhetorical differences between English and other languages would accelerate the acculturation of the students through language exercises and with concrete models that meet audience expectations (Kubota \& Lehner, 2004).

\section{Theoretical background}

\subsection{New contrastive rhetoric and a demand for innovative research lines}

Contrastive rhetoric came to existence when American applied linguist, Robert Kaplan (1966), published his "doodles" article which through five drawings he depicted different rhetorical conventions. Inspired in the heydays of contrastive analysis research, the early contrastive rhetoricians claimed that each language has its own thought patterns which are reflected in its rhetoric. For example, Kaplan (1996) depicted the organization of paragraphs written by native speakers of English as a straight, vertical line to represent the linearity of the organizational pattern. On the other hand, he represented Semitic rhetorical patterns by a zig-zagged line and Oriental rhetoric by a spiral circle (Figure 1).

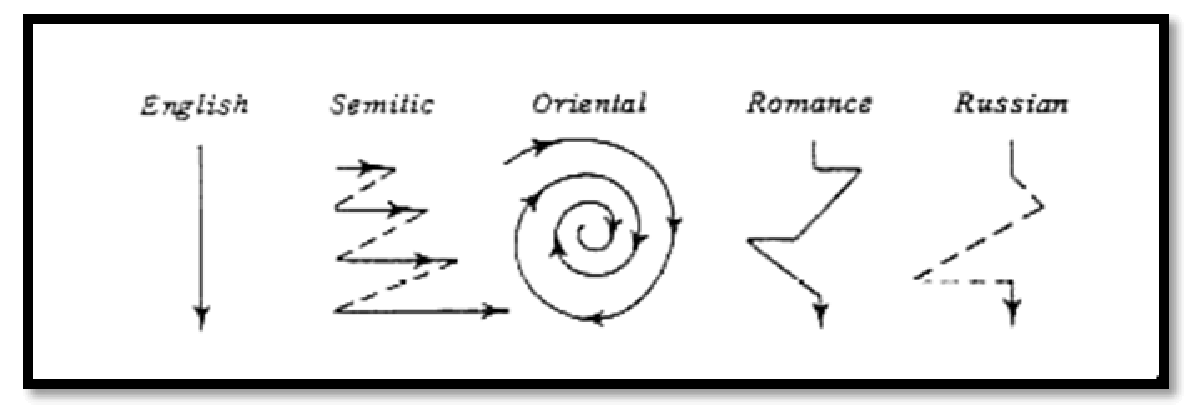

Figure 1. Different modes of discourse structure (Kaplan, 1966, p.14)

As some instances of culture-specific rhetorical patterns, CR research has referred to such points as paragraph organization (Kaplan, 1966); reader-versus-writer responsibility (Hinds, 1987); linear organization structure (Connor, 1987); coordinating conjunctions (Soter, 1988); indirectness devices (Hinkel, 1997, 2002); rhetorical appeals and reasoning strategies (Kamimura \& Oi, 1998); and the use of metatext (Mauranen, 1993; Valero-Garces, 1996).

As it is clear, cross-cultural differences in writing have been the field of research for contrastive rhetoricians since Kaplan's pioneering study (1966). However, initial enthusiasm with CR to improve L2/FL writing pedagogy gradually decreased when soon its simplistic pedagogical practices along with many other criticisms questioned the assumptions of traditional CR. The major criticism concerned the kind of pedagogy CR encouraged. In fact, by overstating the cultural differences in writing and forming a naïve conceptualization of $\mathrm{CR}$, a simplistic and prescriptive pedagogy which was quite product-oriented flourished. Moreover, the view of "other" rhetorical conventions as skewed and problematic in the increasingly multi-cultural writing contexts (both ESL/EFL), perpetuated CR to take an assimilationist and ethnocentric pedagogical stance.

Although Kaplan and other CR scholars (e.g. Cahill, 2003) attempted to qualify and elaborate the original 
claims of CR, teachers, tutors and institutions involved with writing are rarely presented with these elaborations which create its awesome pedagogical consequences (Severino, 1993). This new direction of CR, in the words of Kaplan (1990), is a more general perspective which assumes awareness of the contrastive aspects of two cultures as the first step for ESL/EFL students to attain sensitivity to common errors traceable to their first language and culture. He names $\mathrm{CR}$ as a mechanism through which teachers can explore the problems encountered by the students when composing a text in a second language. Clearly, CR researchers are verifying their original claims through a general process perspective to writing.

This modified view which is referred to as new CR in the literature (Severino, 1993) considers not only the wider contextual factors but also developmental and mental processes in any explanations of second language writers' failures. Undoubtedly, the recent turn to the process of composing a text has offered contrastive rhetoricians a wider perspective to investigating the how of writing process through integrating an awareness of the cross-cultural rhetoric with the precision of a bottom-up exploratory research mode to pinpoint the involved factors in the complicated process of L2/FL writing. This promising balanced perspective to writing which is referred to as process versus post-process challenge in the current theoretical front of L2 composition offers valuable implications for investigating different aspects of the writing process in more depth.

\subsection{Process vs. post-process movement in composition studies}

The inclination to look at writing pedagogy beyond the cognitive approach arose in composition studies during the late 1980s (Berlin, 1988; Bizzell, 1986; Faigley, 1986) and was explicitly named by Trimbure (1994). This social turn which is equated with post-process approach in the related literature was a reaction to the process view that focused on cognition at the expense of other wider social and cultural factors in the composing process.

This post-cognitivist pedagogy represents literacy as an ideological arena and composition as a cultural activity by which writers' position and repositions themselves in relation to their own and others' subjectivities, discourses, practices, and institutions (Trimbur, 1994). Therefore, studying aspects of writing process in relation to cultural, rhetorical and social factors can be framed well within the post-process approach. This innovative research agenda gets more interesting when studying the possible associations between mental and cognitive aspects of writing such as strategies and some cultural patterns with the rhetoric as the most distinguished example.

\subsection{Strategies in composition}

Strategies as informed decisions that writers employ to juggle with the constraints of the writing process (Flower \& Hayes, 1980) have been the focus of many L1 and L2 writing scholars for a long time (Bosher, 1998; Casanave, 2002; Cohen \& Brooks-Carson, 2001; Cumming, 1989; Lei, 2008; Leki,1995, 1998; Raimes, 1987; Riazi,1997; Roca de Larios, Manchon, Murphy \& Marín, 2008; Roca de Larios, Murphy, \& Manchon, 1999; Sasaki, 2000, 2002, 2004, 2007; Villamil \& de Guerrero, 1996; Wong, 2000, 2005; Zamel, 1982, 1983). These studies investigated the strategic behavior of the writers from varying aspects ranging from time allocation strategies in dealing with writing tasks (Roca de Larios et al. , 2008) to the influence of expertise in strategy use (Cumming, 1989) and strategic behavior in its wider social-cognitive context (Riazi, 1997). As a result, a broad range of strategies were identified. For instance, planning strategies concern goal-setting in writing, and rehearsing strategies involve the writer's trying out of ideas before putting them on the paper.

\subsection{Composing strategies and rhetorical context}

Deriving strategies from probing writers' mental processes has been the common practice in the realm of cognition analysis. But writing a text incorporates different components of goals, rhetoric, context, etc. in an interactive manner. In the words of Nelson (1990) there is interactivity between the writer's repertoire of composing strategies, his mental representations of the rhetorical purposes of performing the writing task and his 
Cross-cultural rhetoric awareness and writing strategies of EFL learners: Implications for writing pedagogy

mental representations of audience expectations to shape the process of composing. This assertion confirms that in the process of composing a text cognition and context are interwoven. That is contextual variables might have some correspondences with the strategies that writers might use when composing a text.

A group of scholars have investigated the composition strategies from this wider perspective. As an example, Wong (2005) investigated the probable relation between the composing strategies and writers' mental representations of the intended audience and of the rhetorical purpose. He found that there was significant differences between the extent different writers with diverse rhetorical representations made use of the strategies discovered in the study. In another study aimed to explore the language medium and audience awareness on students' writing, Smith (1993) found that students are acutely aware of how rhetorical conventions vary across languages, and are influenced by how they perceive those conventions.

Later, Xing, Wang, and Spencer (2008) in a study that investigated the potential impact of e-learning on raising overseas students' cultural awareness in writing, drew upon five cross-cultural rhetoric features identified based on the research of Ballard and Clanchy (1991), Cho (1999), Connor (1996), Cortai and Jin (1997), and Schneider and Fujishima (1995). They were inductiveness or deductiveness of the essay, number of paragraphs, topic sentences and topic changes, use of metaphorical or straightforward language and use of explicit discourse markers. The scholars found that raising awareness of the aforementioned cross-cultural rhetoric features was quite effective in improving the writing of the EFL learners.

Overall, the above studies which integrated elements of both cognition and context in the investigation of L2 composition paved the ground for a more extensive view on writing. This innovative line of research which is theoretically supported by the post-process movement in the writing theoretical battleground would offer firm empirical evidences to move toward more multiplicity, the one that L2 writing is practicing at the time (Matsuda, 2003).

\section{The present study}

The literature reviewed above showed the two-way influence of social and cultural elements in the writing process on the one hand and a cognitive, process-based view for the verification of CR claims on the other hand. So, as cultural thought patterns are reflected in the rhetorical conventions specific to each language, the assumption adopted in the present study was that learners with extensive awareness of English rhetorical preferences for composing a text might have a better command of the nuances of rhetorical structure than those who don't and consequently might perform differently from learners with limited knowledge of rhetoric when composing a text. Among numerous factors involved in composing a text, strategic behavior of the writers was particularly investigated. Therefore, rhetoric awareness was selected to see how it affects the strategic behavior of writers both quantitatively and qualitatively in this particular Iranian EFL context. To achieve this goal, the following research question was posed in this study:

$>\quad$ Does English rhetorical awareness have any effect on the strategies that EFL learners employ when composing an argumentative essay?

\section{Methodology}

\subsection{Participants}

Initially, a body of twenty-two advanced female English learners in Hafez Language Institute in Borazjan- a town in southwestern of Iran- was selected to participate in this study. They aged between 17 and 19 years old. Based on the OPT (Oxford Placement Test) proficiency test, they had been selected and then were placed in the advanced level. At the time of study, the learners were attending final days of their classes in the institute and were preparing themselves for the final exam. Later in the study, four learners were selected from this group of 
Ghanbari, B.

learners for a more focused analysis. For the sake of privacy, these four participants are named by their pseudonyms as Faranak, Zarin, Mahin, and Zahra in the rest of the study.

\subsection{Instruments}

Discourse cloze test (DCT) - A discourse cloze test as a measure of rhetoric awareness was designed and used in this study. This test was aimed to provide to what degree advanced participants of the study were aware of the English rhetorical organization (Appendix A). The test has been approved by many scholars (Deys, 1984; Storey, 1997) to develop sensitivity to the operation of different components involved in the discourse.

Writing task - Four learners who finally remained in the study was asked to write an argumentative essay on a prompt provided by the researcher. The writing task asked the participants to write an argumentative essay within a 45 minute time frame.

Think-aloud protocols (TAPs) - In order to obtain rich and real-time data on the cognitive processes of the writers in the study, they were asked to verbalize their thoughts when composing their essay. The TAPs were transcribed for a detailed analysis in the study.

\subsection{Data collection procedure}

To conduct the study, forty learners were randomly selected from Hafez Language Institute. OPT as a measure of English proficiency was administered to them. Finally, a body of twenty two learners who were considered as advanced learners was selected to participate in the rest of the study. The course book was Top Notch authored by Joan Saslow and Allen Ascher (2004) and published by Longman publications. The book consisted of 14 units and covered areas such as vocabulary, vocabulary booster, conversation strategies, grammar, pronunciation, speaking, listening, reading and writing. Writing was explicitly a distinct part and the researcher's personal communication with the learners showed that writing and its related aspects was taken seriously and worked on regularly throughout the course. The DCT was then administered among the participants and they were asked to follow the directions to fill in the blanks deliberately omitted to challenge their rhetorical knowledge. It took them about one hour to complete the test. Table 1 below shows the descriptive statistics associated with the test. Moreover, the reliability estimate of Alpha turned out to be 0.78 which shows a satisfactory level and confirms the inter-consistency of DCT items.

\section{Table 1}

Descriptive statistics for discourse cloze test

\begin{tabular}{cccccc}
\hline$N$ & Minimum & Maximum & Mean & $S D$ & Reliability \\
\hline 22 & 8 & 25 & 14.91 & 4.42 & 0.78 \\
\hline
\end{tabular}

Based on the participants' performance on the test, two groups were formed. The mean performance of the participants was considered as the criterion to divide them into two groups. The first were those who could achieve one SD beyond the mean. This group was called English rhetoric aware learners. Their counterpart group was those learners who comparatively scored low and couldn't approach the criterion level. This group of learners was considered as those who were not good in English discourse or simply called as rhetoric unaware in this study.

To start the main phase of the study, two learners from each group were randomly selected and asked to write an argumentative essay on the provided prompt-i.e. role of English language in their future life. Following the methodology of think-aloud procedure, the learners were asked to verbalize their thoughts while writing. Regarding earlier studies of composing processes (e.g. Arndt, 1987; Bereiter \& Scardamalia, 1987; Flower \& Hays, 1981), think-aloud procedure was utilized to collect data from the participants. The choice of this methodological decision was motivated on the grounds that despite its limitations, concurrent think-aloud is a robust method to develop some understanding of learners' mental processing (Chamot, 2005). 
Prior to think-aloud sessions, a 10-minute training session was conducted individually with each participant to familiarize them with the think-aloud procedure. The training session consisted of two activities: 1) a brief introduction of the think-aloud procedure; 2) a demonstration of think-aloud procedure by the researcher while reading a short passage. Upon the recordings, the observer left the room to avoid any data pollutions that might occur due to her presence such as the participants' avoidance to utter their true thoughts. The recordings were administered in a quiet room in the institute when there were no classes at the time, so the participants were free from any interruptions and could concentrate on their writing. The word limit for their writing was a minimum of 250 words to be conducted within a 45 -minutes time frame. They were allowed to think aloud in any language they felt comfortable with because, as Cohen (1994) pointed out, language choice in think-aloud might require participants' recoding of information, which could cause information loss or alter the original thought processes as a result of such constraints as memory capacity and poor command of the language used for reporting. All the think-aloud reports were recorded by a tape-recorder fully checked for any technical problems prior to the study. The four participants' think-aloud reports were transcribed verbatim to increase the reliability of subsequent data coding (Manchon, Murphy, \& Roca de Larios, 2005).

Later, the participants were invited to take part in a semi-structured stimulated recall interview just after they were done with think aloud procedure to elicit whatever they experienced during their writing task and not mentioned in their TAPs (Appendix B). The researcher conducted the interviews in a friendly environment. They were done in Persian-native language of the participants- and all were recorded.

\subsection{Data Analysis}

Seliger and Shohamy (1989) consider two techniques when dealing with qualitative data analysis. The first is applying an ordering system of categories which already exists at the beginning of the study. The second technique is deriving a set of categories for dealing with text segments from the text itself. The present study followed the second inductive approach. The coding scheme used in this study was developed iteratively on the basis of the author's repeated readings of all the transcriptions. Strategies emerged in the repeated readings were defined, redefined, categorized, and re-categorized (Gregg \& Steinberg, 1980).

Moreover, in order to develop the coding scheme for this study, the researcher consulted different classifications and taxonomies of writing strategies in the literature. As an example, Mu (2005) presents taxonomy of ESL writing strategies which are synthesized from the previous studies on ESL writing strategies (Appendix C). Despite its limitations, such taxonomy which summarizes thirty writing sub-strategies under the five major categories was comprehensive enough to act as a reference point in guiding the researcher when defining and classifying different strategies in the present study. The resultant coding scheme was used by the researcher assistant who was an experienced writing instructor to code a complete think-aloud report independently. The coding scheme that emerged from the second coder was to a great extent similar to the first one. The inter-coder reliability estimate was 0.76 indicating a reasonable degree of consistency between the two coders' categorization of strategies. Those categories which the two coders had differing ideas on were resolved through discussion until complete agreement was achieved and the final strategy coding scheme was prepared (Table 2). Then, all the remaining data were coded by the researcher. All together four TAPs were coded for the analysis.

\section{Results and Discussion}

Quantitative and qualitative analyses of the coded TAPs were conducted to reveal whether the two rhetoric aware writers and the two rhetoric unaware ones differed in their pattern of strategy use. The different strategic behavior of the four writers can be discussed in two parts: first differences in frequency and types of strategies used and second differences in the quality of strategies employed by the two groups when composing the essay. 
Ghanbari, B.

\subsection{Differences in frequency and types of strategy use}

First to know whether the way four participants performed on DCT had any associations with their writing performance, a correlation was conducted. The participants differed in their performance on DCT. The total scores they obtained confirmed this. Faranak and Zarin got 13 and 8 out of 30 respectively. The other participants Mahin and Zahra in the rhetoric aware group obtained 22 and 25 on the test respectively. As Table 3 shows, the degree of rhetorical awareness was considerably associated with the way participants performed on the writing task.

\section{Table 2}

Strategy coding scheme

\begin{tabular}{ll}
\hline I. Topic-related strategies & $\begin{array}{l}\text { a. Comprehending the topic (CT) } \\
\text { b. Revisiting the topic (RT) }\end{array}$ \\
\hline II. Rhetorical strategies & $\begin{array}{l}\text { a. Organization (Org) } \\
\text { b. Use of L1 (UL1) } \\
\text { c. Formatting (Form) }\end{array}$ \\
\hline III. Planning strategies & $\begin{array}{l}\text { a. Global planning (GP) } \\
\text { b. Local planning (LP) }\end{array}$ \\
\hline IV. Rereading strategies & $\begin{array}{l}\text { a. Reading to monitor formal accuracy (RMFA) } \\
\text { b. Reread to organize ideas (ROI) }\end{array}$ \\
& c. Reread to revise content (RRC) \\
\hline V. Questioning strategies & $\begin{array}{l}\text { a. Questioning to generate text (QGT) } \\
\text { b. Questioning to organize text (QOT) }\end{array}$ \\
\hline VI. Rehearsing strategies & Verbalizing ideas or language before writing them down (VIL) \\
\hline VII. Revising strategies & Making changes in the written text, e.g. addition, \\
& deletion substitution, word choice, etc. (Rev)
\end{tabular}

Table 3

Pearson correlation between DCT and writing task

\begin{tabular}{llll}
\hline & & DCT & Writing Task \\
\hline DCT & $\mathrm{r}$ & 1 & 0.921 \\
& Significance (2-tailed) &. & .04 \\
& $\mathrm{~N}$ & 4 & 4 \\
\hline Writing Task & $\mathrm{r}$ & 0.921 & 1 \\
& Significance & 0.04 &. \\
$\mathrm{~N}$ & 4 & 4 \\
\hline
\end{tabular}

For a more detailed analysis, the frequency and types of strategies employed by the four participants are brought in Table 4. Faranak and Zarin in the rhetoric unaware group deployed 10 and 7 strategies out of 14 respectively. This number for the rhetoric aware group was different. While Mahin used 11 strategies, Zahra deployed all 14 strategies for 48 times in her writing. Mahin didn't use 4 strategies in her writing. These included revisiting the topic, formatting, general planning and rereading to revise content. Faranak and Zarin also displayed differential patterns in their use of strategies.

Table 4 shows that Faranak used strategies more frequently compared to Zarin. Topic-related strategies and rereading strategies were two areas that Zarin failed to draw upon. Regarding inter-group differences, it was clear that rhetoric aware group used strategies more frequently than the rhetoric unaware one. Both in types and tokens, rhetoric aware participants outperformed their unaware counterparts. However, to know whether the two groups significantly differed in their strategy use, a Chi-square test was run. Results of the test showed that the two groups of rhetoric aware and rhetoric unaware participants significantly differed (Table 5). 
Cross-cultural rhetoric awareness and writing strategies of EFL learners: Implications for writing pedagogy

Table 4

Frequency of the strategies used by the four participants in their writing

\begin{tabular}{|c|c|c|c|c|}
\hline \multicolumn{5}{|c|}{ Rhetoric unaware Rhetoric aware } \\
\hline Strategy & Faranak & Zarin & Mahin & Zahra \\
\hline $\mathrm{CT}$ & 2 & 0 & 1 & 1 \\
\hline RT & 0 & 0 & 0 & 1 \\
\hline Org & 3 & 2 & 6 & 7 \\
\hline UL1 & 5 & 7 & 8 & 5 \\
\hline Form & 1 & 0 & 2 & 8 \\
\hline GP & 3 & 1 & 0 & 1 \\
\hline LP & 7 & 3 & 5 & 3 \\
\hline RMFA & 4 & 0 & 1 & 3 \\
\hline ROI & 0 & 1 & 5 & 2 \\
\hline RRC & 1 & 0 & 0 & 2 \\
\hline QGT & 0 & 0 & 4 & 1 \\
\hline QOT & 0 & 2 & 5 & 1 \\
\hline VIL & 6 & 7 & 16 & 13 \\
\hline Rev & 4 & 0 & 1 & 0 \\
\hline Total & 36 & 23 & 54 & 48 \\
\hline
\end{tabular}

Table 5

Results of Chi-square test

\begin{tabular}{lcc}
\hline & Rhetoric aware & Rhetoric unaware \\
\hline Chi-Square & 18.357 & $20.571^{\mathrm{b}}$ \\
Df & 10 & 7 \\
Asymp. Sig. & .049 & .004 \\
\hline
\end{tabular}

As Table 5 above shows, familiarity with the rhetoric significantly affected the frequency of strategies used by the two groups. However, our tentative conclusion about differential strategic behavior of the participants was further proved when we examined the quality of strategy use in the two groups. Next section deals with the issue in more detail.

\subsection{Differences in quality of strategy use}

A close look at the TAPs turned up some salient differences in the quality of strategy use between the rhetoric aware and rhetoric unaware writers. However, before investigating the two groups in terms of how of their strategies it should be reminded that these two groups were contrasted only with respect to their awareness of English rhetorical system. In fact, they were asked to write to know if the degree of rhetorical awareness had any implication for their use of strategies while composing an argumentative essay. Not surprisingly the frequency counts derived from the TAPs (Table 4) revealed some areas that both groups performed differently. Rhetorical strategies with the two sub-strategies of organization, and formatting substantially differed among the participants in the two groups. Regarding the use of L1 strategy, both groups evoked it extensively. As it is understood from Table 3, both groups had almost a similar pattern of usage. Also, participants reported in their interviews that compared with English, Persian was an easier and more sophisticated tool to organize ideas, to express thoughts and to think profoundly. However, it should be mentioned that participants in the rhetoric-aware group lamented about the constraints of L1 on L2. As an example, in response to her interview question about whether she thought in English or Persian when composing the essay, Mahin from the rhetoric aware group said:

$I E^{I}$ : Although Persian and thinking in L1 helps a lot when writing in English, it makes my essays

look Penglish! For example, I use the wrong tense, miss articles or use metaphors a lot...

${ }^{1}$ Interview excerpt I 
Ghanbari, B.

Zahra even proceeded to name L1 strategy use as a hindrance in her composing of the essay. She thought that:

IE ${ }^{2}$ : When I'm able to think and write just in English without any throwback to Persian, I can claim that I would be a good English writer. The presence of L1 hurts the quality of my composition and shows me as a Persian writer of English. The thing I really want to avoid!

The way organization and formatting sub-strategies in this category were applied, differed between the groups. Both Zarin and Faranak faced problems in the organization of their essays. In special, they couldn't conclude sensibly. For example, Zarin explicitly talked about her inability to conclude. In one place in her verbalization, she reported that:

TAPEI': I have written three paragraphs so far, but I don't know how to conclude?! I have to think more to be able to conclude. Making conclusion is so difficult! In the first paragraph I talked about myself, in the second it was almost about world and the third paragraph was about my hometown that is English language level in my hometown, but how to conclude and about what?...

Similarly, Faranak, the other participant in the rhetoric unaware group put a startling end to her writing. After some revisions on her essay, she said so:

TAPEII: Now I have finished my essay, so I put an end to it here.

Such a treatment of the essay organization was not observed in the rhetoric aware group. Zahra after writing some well-organized paragraphs ended her essay like that:

TAPEIII: As a conclusion, I can say that when we can feel that we have learnt something that has a role in our life, that we have a great interest, confidence and also we believe ourselves. I'd like to finish my writing with a beautiful quote.

The same problem existed with the introduction of the essay. Participants of rhetoric unaware group were quite confused to begin their writing. After some laborious efforts they abruptly jumped into the essay without any introductory part. Zarin began her writing as so:

TAPEIV: I don't know where to begin. I can just say when I enter university I can improve speaking and other thing and.

Mahin from the rhetoric aware group began her writing with such an introductory sentence:

TAPEV: In today world, it is very necessary to know English. In travelling, in education, in teaching and in life it is required to know English.

Organization strategy as a subcategory within rhetoric strategy category clearly highlighted the degree of mastery of English rhetoric between the two groups. As the frequency counts in Table 4 shows, the rhetoric aware group used this strategy 13 times, while this number for rhetoric unaware group was only 5 .

The other sub-strategy within the rhetoric category, formatting, was considerably employed by the rhetoric aware group. Both Mahin and Zahra were attentive to the mechanics of writing. Zahra particularly paid meticulous attention to this aspect of her writing. In the rhetoric unaware group, however, formatting was not observed and other aspects of writing overshadowed it.

Other differences in strategy use which specifically fell within the cognitive domain related to the use of questioning as well as rehearsing strategies. Regarding questioning to either generate or organize texts, rhetoric aware group was apparently more successful. Rhetoric unaware group didn't use any questioning to generate

${ }^{2}$ Think aloud protocol excerpt I 
Cross-cultural rhetoric awareness and writing strategies of EFL learners: Implications for writing pedagogy

ideas when composing. It was just Zarin that apparently used questioning twice to organize her ideas.

The nature of the questioning strategy was also different from that used with Zahra and Mahin as the rhetoric-aware participants in this study. Both instances of questioning strategy clearly showed that the participants had faced problems in organizing the text. In fact, it was an effort to channel her thoughts to bring a sensible organization to her writing. In one place Zarin said like that:

TAPEVI: How should I conclude now?

In other place, she asked the same question as before:

TAPEVII: I wrote three paragraphs but how to conclude now?

Clearly, these verbalizations were attempts to compensate for their lack of organization knowledge as an important part of rhetoric competence. This argument gets more emphasis when the nature of questioning strategy in the rhetoric-aware group is considered. Some excerpts of Mahin and Zahra are brought below:

Mahin: [After a short review of what was written] Well! What more can I use language for? TAPEVIII

Mahin: What do some people do with language? TAPEIX

Zahra: I will have a good future with English. Well, why? What's the reason? TAPEX

The above TAPEs clearly show that rhetoric aware group was more able in their use of questioning strategy to either generate or organize texts.

The same differing pattern between the two groups was found in the use of rehearsing strategies. Rhetoric-aware group used this strategy strikingly more frequently than the rhetoric unaware group (Table 4).

Mahin and Zahra typically articulated complete sentences before they wrote them down. They used this strategy more effectively and more frequently than the other two participants. They often rehearsed long complete sentences. For example, Zahra verbalized this sentence as so:

TAPEXI: To me, I have a good future in English since I have a great interest in learning foreign languages.

She rehearsed an even longer sentence later as she proceeded in her writing:

TAPEXII: I mean that I like to be a language professor in the future since I have a high self-confidence and I can use those styles of teaching which are in my mind.

By contrast, rhetoric unaware group rehearsed less frequently and when rehearsing, they articulated fragments of sentences in Persian and just one or two words in English. For example, Zarin said:

TAPEXIII: Because of my strong interest, I can learn it faster and more, even I can learn it at advanced level.

Another interesting area of difference between the two groups was concerned with the use of planning strategies as a subcategory within the realm of meta-cognitive strategies. As Table 4 shows, the learners who had a low profile of rhetoric awareness outperformed the rhetoric-aware ones. In fact, the rhetoric aware group planned their writing more locally and rarely planned for their writing in advance (i.e. global planning). When asked about her performance in this strategy category, Mahin who had a typical performance answered so:

IE3: I know who I'm writing to and also why I'm writing, so I quickly and automatically began my essay. I just stopped to think about forthcoming sentences. I mean I knew the general 
structure of my essay as well as its purpose. Therefore, I didn't see it necessary to think about the whole of my writing during the session.

More reliance on planning strategies at both global and local levels among rhetoric unaware group was in line with their particular performance on other strategies. As Faranak put it:

\section{IE4: A constant analysis of the writing (i.e. more planning) was needed to consider all aspects} involved.

In sum, analysis of the TAPs revealed that both groups differed quantitatively and qualitatively in their use of writing strategies. A simple look at the patterns emerged and how strategies were approached by the two groups showed that awareness of rhetoric considerably affected the use of writing strategies by the participants.

\section{Conclusion}

The present study explored whether rhetorical awareness had any correspondence with the writing strategies used by the EFL learners. Findings clearly showed that rhetoric awareness had a differential effect on the strategies used by EFL learners when composing in English. Strategic behavior of the learners was affected by EFL learners' awareness of the cultural nuances of the way text was expanded and organized.

The four writers showed a seemingly different repertoire of writing strategies (both quantitatively and qualitatively). The way they relied upon and controlled different strategies was to a large extent due to their command of rhetoric awareness. As evidence, it was under the category of rhetorical strategies that the writers demonstrated the utmost differences. Relatively speaking, better performance in other categories of strategies also indicates that rhetoric aware learners were more ready to make use of a broad range of composition strategies to facilitate the process of writing. However, the two groups showed distinct patterns of performance regarding individual strategies. For example, in the category of planning strategies or revision strategies, the writers in the unaware group performed better than those in rhetoric-aware. As an extension to the present study, it would be illuminating to carry out investigations into different patterns of performance on individual strategies and to explore any relationship among larger domains of strategies, e.g. meta-cognitive, cognitive, etc.

Some tentative implications can be derived from the findings of this study for EFL writing instruction. One implication for the writing pedagogy is that it should look beyond the cognitive approaches to writing which views writing as a problem-solving task and emphasizes the complex, recursive and individual nature of the writing process independent of cultural and historical influences. Writing as a social act that occurs in a specific context and for specific audience and purposes should be studied in a wider background. In such a way, rhetoric as the culture-specific way of organizing the text can be a good index regarding the degree of the familiarity of the EFL writers with the hidden sociocultural nuances involved in any writing task. Having in mind the potential of rhetoric in the EFL learners' composition, EFL writing instructors are required to separately focus on this important aspect of writing.

Similarly, EFL writing teachers might find it useful to emphasize English rhetorical conventions as an important element in improving EFL learners' compositions. The domain of rhetoric can well be expanded beyond the limited categories in this study and cover areas more complicated.

Although the present protocol-based study has revealed some interesting findings about EFL writers' strategy use, it has a number of limitations, and further research is needed before firm generalizations be made. The first limitation concerns the reliability of the TAPs. Despite its popularity among researchers who are interested in the cognitive processes of composing, it was found that the writers in both groups were not good at introspecting while writing. They sometimes paused and kept silent. There is good reason to believe that some of their cognitive activities were not reported. In future qualitative research using the think-aloud procedure, careful and skillful prompting should be employed to obtain rich data about psychological processes. 
Cross-cultural rhetoric awareness and writing strategies of EFL learners: Implications for writing pedagogy

Another limitation is that based on the data from the TAPs, an interview and a single writing task, this study investigated strategies used by four proficient EFL learners in a particular context which are by no means exhaustive. To enrich our understanding of writing strategy use, more individuals and contexts need to be included in future research. Also, due to the particular Iranian EFL context, it is inappropriate to generalize our findings to other EFL learners.

Acknowledgments: The researcher is grateful to Hafez Language Institute in Borazjan, Iran for the cooperation in this study. Moreover, the author extends her appreciations to the four participants in this study.

\section{References :}

Arndt, V. (1987). Six writers in search of texts: A protocol-based study of L1 and L2 writing. ELT Journal, 41(4), 257-267. http://dx.doi.org/10.1093/elt/41.4.257

Ballard, B., \& Clanchy, J. (1991). Assessment by misconception: Cultural influences and intellectual traditions. In L. Hamp-Lyons (Ed.), Second language writing in academic contexts, (pp. 122-134). Norwood, NJ: Ablex Publishing Corporation.

Benda, J. (1999). Qualitative studies in contrastive rhetoric: An analysis of composition research. Retrieved December 18, 2007, from http://web.syr.edu/jpbenda/methcomm.htm

Bereiter, C., \& Scardamalia, M. (1987). The psychology of written composition. Mahwah, NJ: Lawrence Erlbaum Associates.

Berlin, J. A. (1988). Rhetoric and ideology in the writing class. College English, 50, 477-494. http://dx.doi.org/10.2307/377477

Bizzell, P. (1986). Composing processes: An overview. In A. Petrosky \& D. Bartholomae (Eds.), The teaching of writing (pp. 49-70). Chicago: University of Chicago Press.

Bosher, S. (1998). The composing processes of three Southeast Asian writers at the post-secondary level: An exploratory study. Journal of Second Language Writing, 7(2), 205-241. http://dx.doi.org/10.1016/S1060-3743(98)90013-3

Braddock, R., Lloyd-Jones, R., \& Schoer, L. (1963). Research in written composition. Urbana, IL: NCTE.

Cahill, D. (2003). The myth of the turn in contrastive rhetoric. Written Communication, 20(2), 170-194. http://dx.doi.org/10.1177/0741088303020002003

Casanave, C. P. (2002). Writing games: Multicultural case studies of academic literacy practices in higher education. Mahwah, NJ: Lawrence Erlbaum Associates.

Chamot, A. U. (2005). Language learning strategy instruction: Current issues and research. Annual Review of Applied Linguistics, 25, 112-130. http://dx.doi.org/10.1017/S0267190505000061

Cho, J. H. (1999). Contrastive Rhetoric. Unpublished doctoral dissertation. Bowling Green State University, Bowling Green, OH. Retrieved December 18, 2007, from http://faculty.fullerton.edu/jcho/dispreface.htm

Cohen, A. D. (1994). Verbal reports on learning strategies. TESOL Quarterly, 28, 678-684.

Cohen, A., \& Brooks-Carson, A. (2001). Research on direct versus translated writing: Students' strategies and their results. The Modern Language Journal, 85(2), 169-188.

http://dx.doi.org/10.1111/0026-7902.00103

Connor, U. (1987). Argumentative patterns in student essays: Cross-cultural differences. In U. Connor \& R. Kaplan (Eds.), Writing across languages: Analysis of L2 text (pp. 57-71). Reading, MA: Addison-Wesley.

Connor, U. (1996). Contrastive rhetoric: Cross-cultural aspects of second-language writing. Cambridge: Cambridge University Press. http://dx.doi.org/10.1017/CBO9781139524599

Cortai, M., \& Jin, L. (1997). Communication for learning across cultures. In D. McNamar \& R. Harris (Eds.), Overseas students in higher education: Issues in teaching and learning (pp. 76-90). New York: Routledge.

Cumming, A. (1989). Writing expertise and second-language proficiency. Language Learning, 39(1), 81-141. 
Ghanbari, B.

http://dx.doi.org/10.1111/j.1467-1770.1989.tb00592.x

Currie, P. (1993). Entering a disciplinary community: Conceptual activities required to write for one introductory university course. Journal of Second Language Writing, 2, 101-117.

http://dx.doi.org/10.1016/1060-3743(93)90012-R

Faigley, L. (1986). Competing theories of process: A critique and proposal. College English, 48(6), 527-542. http://dx.doi.org/10.2307/376707

Flower, L., \& Hayes, J. R. (1980). The cognition of discovery: Defining a rhetorical problem. College Composition and Communication, 31, 21-32. http://dx.doi.org/10.2307/356630

Flower, L., \& Hayes, J. R. (1981). A cognitive process theory of writing. College Composition and Communication, 32, 365-387. http://dx.doi.org/10.2307/356600

Gregg, L. W., \& Steinberg, E. R. (1980). Cognitive processes in writing. Hillsdale, NJ: Lawrence Erlbaum Associates.

Hansen, J. G. (2000). Interactional conflicts among audience, purpose and content knowledge in the acquisition of academic literacy in an EAP Course. Written Communication, 17(1), 27-52. http://dx.doi.org/10.1177/0741088300017001002

Hinds, J. (1987). Reader versus writer responsibility: A new typology. In U. Connor \& R. Kaplan (Eds.), Writing across languages: Analysis of L2 text (pp. 141-152). Reading, MA: Addison-Wesley.

Hinds, J. (1990). Inductive, deductive, quasi-inductive: Expository writing in Japanese, Korean, Chinese, and Thai. In U. Connor \& A. M. Johns (Eds.), Coherence in writing: Research and pedagogical perspectives (pp. 87-110). Alexandria, VA: TESOL.

Hinkel, E. (1997). Indirectness in L1 and L2 academic writing. Journal of Pragmatics, 27, 361-386. http://dx.doi.org/10.1016/S0378-2166(96)00040-9

Hinkel, E. (2002). Second language writers' text: Linguistic and rhetorical features. Mahwah, NJ: Lawrence Erlbaum.

Horowitz, D. (1986). What professors actually require academic skills for the ESL classroom. TESOL Quarterly, 20(3), 445-462. http://dx.doi.org/10.2307/3586294

Hu, G., \& Chen, B. (2007). A protocol-based study of university-level Chinese EFL learners' writing strategies. English Australia Journal, 23(2), 37-56.

Kamimura, T., \& Oi, K. (1998). Argumentative strategies in American and Japanese English. World Englishes, 17(3), 307-323. http://dx.doi.org/10.1111/1467-971X.00106

Kaplan, R. B. (1966). Cultural thought patterns in intercultural education. Language Learning, 16(1-2), 1-20. http://dx.doi.org/10.1111/j.1467-1770.1966.tb00804.x

Kaplan, R. B. (1990). Writing in a multilingual/multicultural context: What is contrastive about contrastive rhetoric? The Writing Instructor, Fall, 51-62.

Kaplan, R. B. (1997). Introducing contrastive rhetoric: What is it? What is it for? How can it be used? SPELT Newsletter, 12, 2-28.

Kubota, R. \& Lehner, A. (2004). Toward critical contrastive rhetoric. Journal of Second Language Writing, 13(1), 7-27. http://dx.doi.org/10.1016/j.jslw.2004.04.003

Lei, X. (2008). Exploring a sociocultural approach to writing strategy research: Mediated actions in writing activities. Journal of Second Language Writing, 17(4), 217-236. http://dx.doi.org/10.1016/j.jslw.2008.04.001

Leki, I. (1991). Twenty five years of contrastive rhetoric. TESOL Quarterly, 25(1), 123-143. http://dx.doi.org/10.2307/3587031

Leki, I. (1995). Coping strategies of ESL students in writing tasks across the curriculum. TESOL Quarterly, 29(2), 235-260. http://dx.doi.org/10.2307/3587624

Leki, I. (1997). Cross-talk: ESL issues and contrastive rhetoric. In C. Severino, J. Guerra, \& J. Butler (Eds.), Writing in multicultural settings (pp. 234-244). NY: The Modern Language Association of America.

Leki, I. (1998). Academic writing: Exploring processes and strategies (2nd ed.). Cambridge: Cambridge University Press.

Liebman, J. (1992). Toward a new contrastive rhetoric: Differences between Arabic and Japanese rhetorical 
instruction. Journal of Second Language Writing, 1(2), 141-165.

http://dx.doi.org/10.1016/1060-3743(92)90013-F

Manchon, R. M., Murphy, L., \& Roca de Larios, J. (2005). Using concurrent protocols to explore L2 writing process: Methodological issues in the collection and analysis of data. In P. K. Matsuda \& T. Silva (Eds.), Second language writing research: Perspectives on the process of knowledge construction (pp. 191-205). Mahwah, NJ: Erlbaum.

Martin, J. E. (1992). Towards a theory of text for contrastive rhetoric: An introduction to issues of text for students, practitioners of contrastive rhetoric (Series XIII, Vol.19). NY: American University Studies.

Matsuda, P. K. (1997). Contrastive rhetoric in context: A dynamic model of L2 writing. Journal of Second Language Writing, 6(1), 45-60. http://dx.doi.org/10.1016/S1060-3743(97)90005-9

Matsuda, P. K. (2003). Process and post-process: A discursive history. Journal of Second Language Writing, 12(1), 65-83. http://dx.doi.org/10.1016/S1060-3743(02)00127-3

Mauranen, A. (1993). Contrastive ESP rhetoric: Metatext in Finnish-English economics texts. English for Specific Purposes, 12, 3-22. http://dx.doi.org/10.1016/0889-4906(93)90024-I

Mohan, B., \& Lo, W. A. Y. (1985). Academic writing and Chinese students: Transfer and developmental factors. TESOL Quarterly, 19(3), 515-534. http://dx.doi.org/10.2307/3586276

Mu, C., (2005). A taxonomy of ESL writing strategies. In Proceedings redesigning pedagogy: Research, policy, practice, pp. 1-10, Singapore.

Nelson, J. (1990). This was an easy assignment: examining how students interpret writing tasks. Research in the Teaching of English, 24(4), 362-396.

Raimes, A. (1987). Language proficiency, writing ability, and composing strategies: A study of ESL college student writers. Language Learning, 37(3), 439-469. http://dx.doi.org/10.1111/j.1467-1770.1987.tb00579.x

Riazi, A. (1997). Acquiring disciplinary literacy: A social-cognitive analysis of text production and learning among Iranian graduate students of education. Journal of Second Language Writing, 6(2), 105-137. http://dx.doi.org/10.1016/S1060-3743(97)90030-8

Roca de Larios, J., Mancho’n, R., Murphy, L., \& Marín, J. (2008). The foreign language writer's strategic behavior in the allocation of time to writing processes. Journal of Second Language Writing, 17(1), 30-47. http://dx.doi.org/10.1016/j.jslw.2007.08.005

Roca de Larios, J., Murphy, L., \& Mancho'n, R. (1999). The use of restructuring strategies in EFL writing: A study of Spanish learners of English as a foreign language. Journal of Second Language Writing, 8(1), 13-44. http://dx.doi.org/10.1016/S1060-3743(99)80111-8

Sasaki, M. (2000). Toward an empirical model of EFL writing processes: An exploratory study. Journal of Second Language Writing, 9(3), 259-291. http://dx.doi.org/10.1016/S1060-3743(00)00028-X

Sasaki, M. (2002). Building an empirically-based model of EFL learners' writing processes. In S. Ransdell \& M. Barbier (Eds.), New directions for research in L2 writing (pp. 49-80). Dordrecht, Netherlands: Kluwer Academic Publishers. http://dx.doi.org/10.1007/978-94-010-0363-6_3

Sasaki, M. (2004). A multi-data analysis of the 3.5-year development of EFL student writers. Language Learning, 54(3), 525-582. http://dx.doi.org/10.1111/j.0023-8333.2004.00264.x

Sasaki, M. (2007). Effects of study-abroad experiences on EFL writers: A multiple-data analysis. The Modern Language Journal, 91(4), 602-620. http://dx.doi.org/10.1111/j.1540-4781.2007.00625.x

Schneider, M. L., \& Fujishima, N. K. (1995). When practice doesn't make perfect: The case of a graduate ESL student. In D. Belcher, \& G. Braine (Eds.), Academic writing in a second language: Essays on research \& pedagogy (pp. 231-265). Norwood, NJ: Ablex Publishing Corporation.

Seliger, H. \& Shohamy, E. (1989). Second language research methods. Oxford: Oxford university press.

Severino, C. (1993). The Doodles in context: Qualifying claims of CR. The Writing Center Journal, 14(1), 44-61.

Smith, W. M. (1993). Students as contrastive rhetoricians: Examining ESL students' perceptions of L1 and L2 rhetorical conventions. Arizona Working Papers in SLAT, 12, 79-98.

Soter, A. O. (1988). The second language learner and cultural transfer in narration. In A. Purves (Ed.), Writing 
Ghanbari, B.

across languages and cultures: Issues in contrastive rhetoric (pp. 177-205). Thousand Oaks, CA: Sage Publications.

Storey, P. (1997). Examining the test-taking process: a cognitive perspective on the discourse cloze test. Language Testing Journal, 14(2), 214-231. http://dx.doi.org/10.1177/026553229701400205

Trimbur, J. (1994). Taking the social turn: Teaching writing post-process. College Composition and Communication, 45(1), 108-118. http://dx.doi.org/10.2307/358592

Valero-Garces, C. (1996). Contrastive ESP rhetoric: Metatext in Spanish-English economics texts. English for Specific Purposes, 15(4), 279-294. http://dx.doi.org/10.1016/S0889-4906(96)00013-0

Van Lier, L. (2004). The ecology and semiotics of language learning: A sociocultural perspective. In X. Lei, Exploring a sociocultural approach to writing strategy research: Mediated actions in writing activities. Journal of Second Language Writing, 17, 217-236.

Villamil, O. S., \& de Guerrero, M. C. M. (1996). Peer revision in the L2 classroom: Social-cognitive activities, mediating strategies, and aspects of social behavior. Journal of Second Language Writing, 5(1), 51-75. http://dx.doi.org/10.1016/S1060-3743(96)90015-6

Wong, A. T. Y. (2000). A study of cognition in context: The composing strategies of advanced writers in an academic context. Unpublished doctoral thesis, The University of Hong Kong, Hong Kong.

Wong, A. T. Y. (2005). Writers' mental representation of the intended audience and of the rhetorical purpose for writing and the strategies that they employed when they composed. System, 33(1), 29-47. http://dx.doi.org/10.1016/j.system.2004.06.009

Xing, M., Wang, J. \& Spencer, K. (2008). Raising students' awareness of cross-cultural contrastive rhetoric in English writing via an E-learning course. Language Learning \& Technology, 12(2), 71-93.

Zamel, V. (1983). The composing processes of advanced ESL students: Six case studies. TESOL Quarterly, 17(2), 165-187. http://dx.doi.org/10.2307/3586647

Zamel,V. (1982). Writing: The process of discovering meaning. TESOL Quarterly, 10(1), 67-76. http://dx.doi.org/10.2307/3585940 


\section{Appendix A}

Name:

Age:

Gender:

Last Degree:

Occupation:

\section{Discourse Cloze Test}

Directions: This test is intended to measure your awareness of English rhetorical patterns, i.e. how to put sentences and paragraphs into larger units when writing an essay. Please read the following passage and write the word that best completes each blank. In addition you should answer the questions below the passage. Thanks for your cooperation!

\section{What do you think of English courses in the universities?}

University students do not have to take English courses unless the courses provide them with what they need. They have already taken a long...1....... of studying English from kindergarten, to junior school,...2... to high school ......... the.....4... extends to university. There is no doubt that they have spent too much time on learning the language, including its structure and vocabulary. It is time for them to use it .....5... to put what they have learnt into practice. Motivation is the key for individual's learning, ...6...... is indicated by a survey from South Medical University. A questionnaire on the needs of English learning for the tertiary students was sent out to 300 students and 243 returned. $66 \%$ of the responses expressed that they had passed the highest national English test CET6 ...7... 6.1\% passed international English tests .....8.... TOL, EPT, WSK. The result reveals that the university students have already had a very strong English background. The open questions of the questionnaire ...9.... show that most students expressed their strongly desire to use the language ...10.........in presentation, in translation .....11... in cultural exchange. The aim of the English learners is very practical: real-life communication in both oral ...12..... written form. .....13........, there is discrepancy between expectation and reality: university English courses are still about grammar points, vocabulary details, .....14........ students do not feel learning anything new. The lack of oral and writing in English courses remains a problem in the curriculum .....15.... no wonder many students prefer not to go to English courses,.....16... surfing on the internet reading authentic English materials instead. It will be beneficial for the students ...17.....the university can arrange two types of English courses: one is oral English in class where students are encouraged to express themselves in English. The presenters can collect ideas from other students ...18.... improve their presentation skills. It will ...19..... be good fun for all the students no matter which discipline they are from, ...20..... they can sit down ...21..... share with what work they are currently doing, .....22... expands their view of the world. The other is writing course after class. Students can do research on a certain topic .....23... give their opinion to the e-forum. As other students are from different areas, they might see it from other angles...24.... comment...25... add in new ideas. The teacher can guide them to use the appropriate expressions and structures to express their ideas. Students can ...26.... be confident to use the English in real-life situations.

1. What do you think is the theme or main idea of the above passage?

2. What is the topic sentence of the first paragraph?

3. What is the topic sentence of the second paragraph?

4. What is the topic sentence of the third paragraph?

5. What is the topic sentence of the fourth paragraph? 
Ghanbari, B.

\section{Appendix B}

\section{Interview questions about writing experience}

1. Can you explain the whole steps that you took when writing?

2. Did you think in Persian or English while composing the passage?

3. Did the experience of thinking aloud disturb you while writing?

4. What strategy/strategies were of most use to you?

5. How do you look at your writing final draft?

\section{Appendix C}

Taxonomy of ESL Writing Strategies (Mu , 2005, p.9)

\begin{tabular}{|l|l|l|}
\hline \multicolumn{1}{|c|}{ Writing strategies } & \multicolumn{1}{|c|}{ Sub-strategies } & \multicolumn{1}{c|}{ Speculations } \\
\hline \multirow{4}{*}{ Rhetorical strategies } & Organization & Beginning/development/ending \\
\cline { 2 - 3 } & Use of L1 & Translate generated idea into ESL \\
\cline { 2 - 3 } & Formatting/Modeling & Genre consideration \\
\cline { 2 - 3 } & Comparing & Different rhetorical conventions \\
\hline \multirow{5}{*}{ Meta-cognitive strategies } & Planning & Finding Focus \\
\cline { 2 - 3 } & Monitoring & Checking and identifying problem \\
\cline { 2 - 3 } & Monitoring & Reconsidering written text, goals \\
\hline \multirow{5}{*}{ Cognitive strategies } & Generating ideas & Repeating, lead-in, inferencing, etc. \\
\cline { 2 - 3 } & Revising & Making changes in plan, written text \\
\cline { 2 - 3 } & Elaborating & Extending the contents of writing \\
\cline { 2 - 3 } & Clarification & Disposing of confusions \\
\cline { 2 - 3 } & Retrieval & Getting information from memory \\
\cline { 2 - 3 } & Rehearsing & Trying out ideas or language \\
\cline { 2 - 3 } & Summarizing & Synthesizing what has read \\
\hline Communicative & Avoidance & Avoiding some problem \\
\cline { 2 - 3 } strategies & Reduction & Give up some difficulties \\
\cline { 2 - 3 } & Sense of readers & Anticipating readers' response \\
\hline \multirow{3}{*}{$\begin{array}{l}\text { Social/Affective } \\
\text { strategies }\end{array}$} & Resourcing & Getting support from professor, peers \\
\cline { 2 - 3 } & Getting feedback & Dissolve the load of the task \\
\cline { 2 - 3 } & Assigning goals & Reducing anxiety \\
\cline { 2 - 3 } & Rest/deferral & \\
\hline
\end{tabular}

